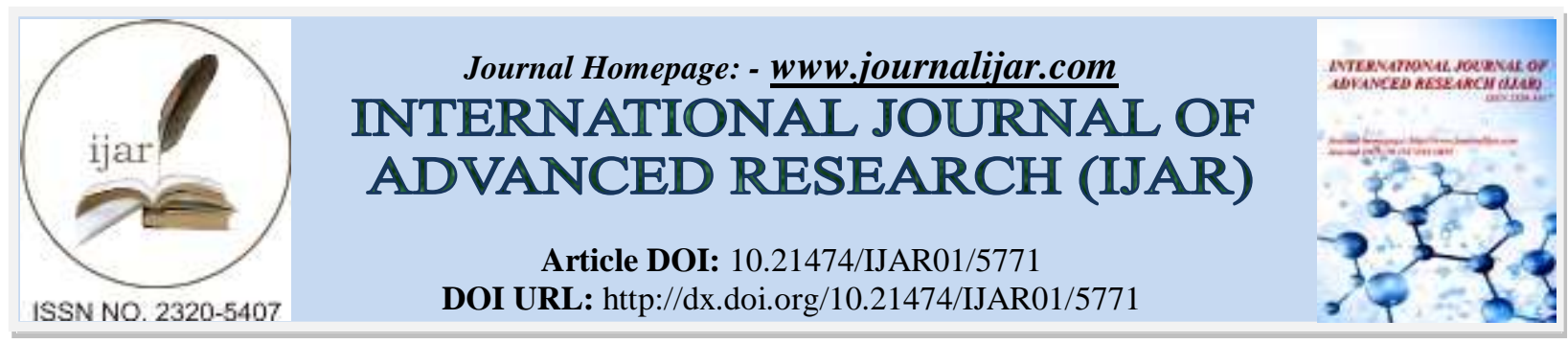

RESEARCH ARTICLE

\title{
GENETIC CHARACERIZATION OF NDV STRAINS ISOLATED FROM BROILER CHICKENS OUTBREAKS IN EGYPT.
}

\author{
EL-Dabae. W. H. ${ }^{1}$, Hussein. H. A $^{2}$, Ata. Nagwa. S. ${ }^{1}$ and Reda. I. $M^{2}$. \\ 1. Microbiology and Immunology Department, Veterinary Research Division, National Research Center. \\ 2. Virology Department, Faculty Of Veterinary Medicine, Cairo University.
}

\section{Manuscript Info}

Manuscript History

Received: 04 September 2017

Final Accepted: 06 October 2017

Published: November 2017

Key words:-

NDV, nested PCR, sequence analysis and phylogenetic tree.

\begin{abstract}
In the present study, NDV strains isolated from outbreaks in broiler farms in Egypt were molecularly characterized in 2009. Field samples were collected from different 50 broiler flocks distributed in Egyptian governorates showing characteristic NDV signs and post mortum lesions. Nested PCR was carried out by application of RT-PCR for amplification of regions of genes encoded for the fusion and matrix proteins followed by second PCR, the second PCR products (about $300 \mathrm{bps}$ ) were sequenced for characterization of the virus. MEGA program version 4 was used for Phylogenetic analysis of sequenced NDV local isolates as well as ten selected known global (I-X) NDV genotypes. The results revealed that those isolates were related to genotype II (Lasota like strain) (Accession No. AF077761) while one isolate (NDV Giza VRLCU 09 23) was related to APMV1-ChShandong-SRZ-03 strain (Accession No. DQ417112). The occurrence of breaks in vaccinated flocks suggests that massive vaccination with live vaccines and use of more than one type of vaccine leads to evolving of new field lentogenic strains which may be classified as new genotypes due to mutations leading to increase outbreaks and the newly strains are conflicted with virus field infection.
\end{abstract}

Copy Right, IJAR, 2017,. All rights reserved.

\section{Introduction:-}

Newcastle disease (ND) is one of the most serious and lethal avian diseases, resulting in heavy losses within the poultry industry worldwide (Aldous and Alexander 2001). Its causative agent, virulent Newcastle disease virus (NDV), is classified as the Avulavirus genus within the paramyxovirinae subfamily of the paramyxoviridae (Fauquet and Fargette, 2005). It is a negative-sense, single stranded, non-segmented, enveloped RNA virus (Alexander and Senne, 2008). The NDV genome is composed of six genes and encodes their corresponding six structural proteins: nucleoprotein (NP), phosphoprotein $(\mathrm{P})$, matrix $(\mathrm{M})$, fusion $(\mathrm{F})$, hemagglutinin-neuraminidase (HN), and the RNA polymerase (L) (Lambs and Parks 2007).

The primary molecular determinant for NDV pathogenecity is the amino acids sequence at F protein cleavage site or restriction sites of the $\mathrm{F}$ gene and the ease by which cellular proteases cleave the fusion protein Thus, The differences in $\mathrm{F}$ gene sequences that correlate with different virulent phenotypes have been prime targets for molecular approaches to identify and characterize NDV isolates (De Leeuw et al., 2005). Along with biological

Corresponding Author: - EL-Dabae. W. H.

Address: - Microbiology and Immunology Department, Veterinary Research Division, National Research 
virulence determination, OIE accepts reporting of the F protein cleavage site sequence of NDV isolates as a virulence criterion (Berinstein et al., 2001).

Emergence of new virulent genotypes from epizootics and year to year changes in sequence of NDV of low and high virulence implies that distinct genotypes of NDV are simultaneously evolving at different geographic locations across the globe (Miller et al., 2010).

The main objective of the current study is molecular identification and characterization of NDV field strains isolated from breaks in Egypt.

\section{Material and Methods:-}

Samples:-

- Field tissue samples including different internal organs (Trachea, cecal tonsil, spleen, proventriculus, gizzard and intestine including contents) were collected from 50 different broiler flocks in some egyptian governorates (ElQaliubia, El-Giza, El-Behira, El-Menufia, El-Fayoum, El-Sharqia, El-Dakhalia and EL-Gharbia) showing signs and post mortum lesions characteristic to NDV.

-The preparation of sample was carried out according to (Burleson et al., 1994).

RNA extraction:-

-Viral RNA was extracted using SV total RNA isolation system (Promega) according to the manufacturer's instructions with minor modifications (seal et al., 1995).

Nested PCR:-

A-The nested PCR was carried out by application of RT-PCR using M1 sense primer and F1 antisense primer (Mase et al., 2002) as indicated in (table 1) with cycling protocol (table 2).

Table (1):- Sequence of different primers used in nested PCR.

\begin{tabular}{|c|c|}
\hline Primer & sequence \\
\hline M1 sense & 5-TTC-TCT-AGC-AGT-GGG-ACA-GC-3 \\
\hline F1 antisense & 5-CAT-CTTCCC- AAC-TGC-CAC-TG -3 \\
\hline M2 sense & 5-TGG-AGC-CAA-ACC-CGC-ACC-TGC-GG-3 \\
\hline antisense & 5-GGA-GGA-TGT-TGG-CAG-CAT-T-3 \\
\hline
\end{tabular}

Table (2):- Cycling protocol for amplification of 921 bp using external primers (F1 and M1).

\begin{tabular}{|l|c|c|c|}
\hline \multicolumn{1}{|c|}{ Step } & Temperature & Time & cycles \\
\hline (1) RT & $50^{\circ} \mathrm{C}$ & $15 \mathrm{~min}$. & 1 \\
\hline (2) Pre PCR & $95^{\circ} \mathrm{C}$ & $2 \mathrm{~min}$. & \multirow{2}{*}{40} \\
\hline (3) Denaturation & $95^{\circ} \mathrm{C}$ & $30 \mathrm{sec}$. & \\
\hline (4) Anneling & $52^{\circ} \mathrm{C}$ & $30 \mathrm{sec}$. & 1 \\
\hline (5) Polymerization & $72^{\circ} \mathrm{C}$ & $1 \mathrm{~min}$. & 1 \\
\hline (6) Final extension & $72^{\circ} \mathrm{C}$ & $5 \mathrm{~min}$. & 1 \\
\hline (7) Cooling & $4^{\circ} \mathrm{C}$ & $/ /$ & \\
\hline
\end{tabular}

B- Second cycle of PCR using the first cycle PCR product as template, M2, F2 primers and thermo PCR master mix with cycling protocol (table 3 ).

Table (3):- Cycling protocol for amplification of 766 bp fragment using internal primers (F2 and M2).

\begin{tabular}{|l|c|c|c|}
\hline \multicolumn{1}{|c|}{ Step } & Temperature & Time & cycles \\
\hline (1) Pre PCR & $94^{\circ} \mathrm{C}$ & $1 \mathrm{~min}$. & 1 \\
\hline (2) Denaturation & $94^{\circ} \mathrm{C}$ & $30 \mathrm{sec}$. & 35 \\
\hline (3) Anneling & $54^{\circ} \mathrm{C}$ & $30 \mathrm{sec}$. & \\
\hline (4) Polymerization & $72^{\circ} \mathrm{C}$ & $45 \mathrm{sec}$. & 1 \\
\hline (5) Final extension & $72^{\circ} \mathrm{C}$ & $7 \mathrm{~min}$. & 1 \\
\hline (6) Cooling & $4^{\circ} \mathrm{C}$ & $/ /$ & 1 \\
\hline
\end{tabular}


The PCR products were analyzed using agrose gel electrophoresis according to (Sambrook et al., 1989) and eluted from gel and sent to gene analysis unit, Vacsera, Agouza, Giza, Egypt for sequencing using ABI PRISM 310 automated DNA sequencer. The sequence data and phylogenetic trees for NDV were constructed using BioEdit software and version 4 of MEGA program, respectively.

\section{Results:-}

1- Results of RT-PCR on extracted viral RNA for amplification of 921 bp product of $\mathrm{F}$ and M genes NDV (first product of amplification)

The RT-PCR assay revealed visible bands in unexpected site about 200-300 bp of samples 8, 10 (obtained both from El-Behira 2009), 14 (obtained from El-Fayoum 2009), 15, 17, 19 (obtained from EL-Gharbia 2009 ), 25 (obtained from Giza 2009) and other samples showed negative results. Samples 17, 25 showed strong bands and the positive control vaccinal strain Lasota gives 921 bp products (expected site).

As no enough products were obtained secondary amplification was performed as a second step.

\section{2-Results of second PCR assay for amplification of 766 bp covering $420 \mathrm{bp}$ of $\mathrm{F}$ gene}

The results of the second PCR revealed that 7 samples out of examined samples were positive for amplification of the expected band after separation on $1.5 \%$ agrose stained with ethidium bromide these samples were designated as shown in (table 4).

Table (4):- Designation and accession numbers of positive samples.

\begin{tabular}{|l|l|l|}
\hline Sample No. & \multicolumn{1}{|c|}{ Designation } & \multicolumn{1}{c|}{ Gene bank Accession No. } \\
\hline 9 (Behaira) & NDV/II/Behaira/VRLCU*/9/09 & HQ455806 \\
\hline 17 (Gharbia) & NDV/II/Gharbia/VRLCU*/17/09 & HQ455807 \\
\hline 18 (Gharbia) & NDV/II/Gharbia/VRLCU*/18/09 & HQ455808 \\
\hline 19 (Gharbia) & NDV/II/Gharbia/VRLCU*/19/09 & HQ455809 \\
\hline 23 (Giza) & NDV/II/Giza/VRLCU*/23/09 & HQ455810 \\
\hline 24 (Giza) & NDV/II/Giza/ VRLCU*/24/09 & HQ455811 \\
\hline 27 (Giza) & NDV/II/Giza/ VRLCU*/27/09 & HQ455805 \\
\hline
\end{tabular}

* Virology Research Lab. Cairo University (faculty of veterinary medicine).

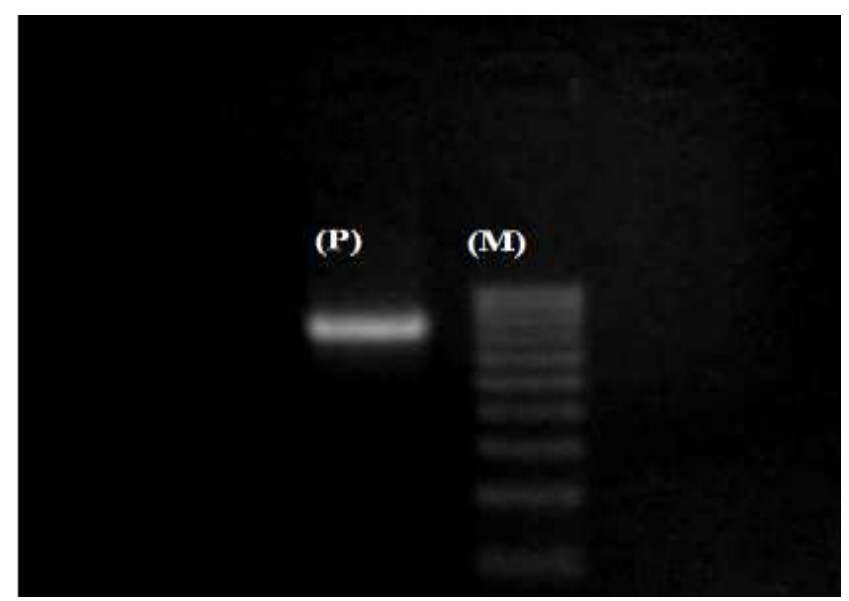

Figure 1

PCR product with 766 bp molecular size of the positive control vaccinal strain Lasota (P) along with the 100 bp molecular weight marker $(M)$ gives band at 766 bp (Second amplification).

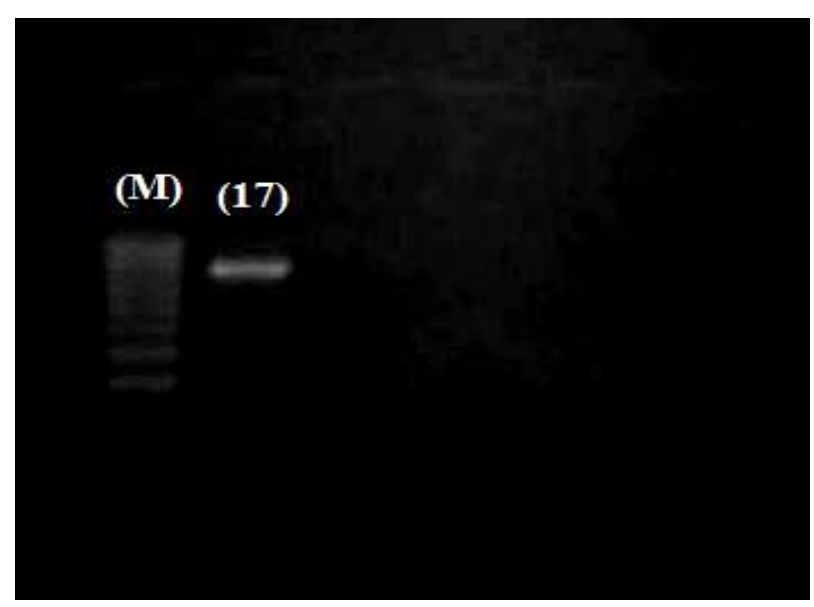

Figure 2

PCR product with766 bp molecular size of sample 17 along with the 100 bp molecular weight marker (M), gives band at 766 bp (Second amplification). 


\section{(19) (23) (M) (27) (18) (9) (24)}

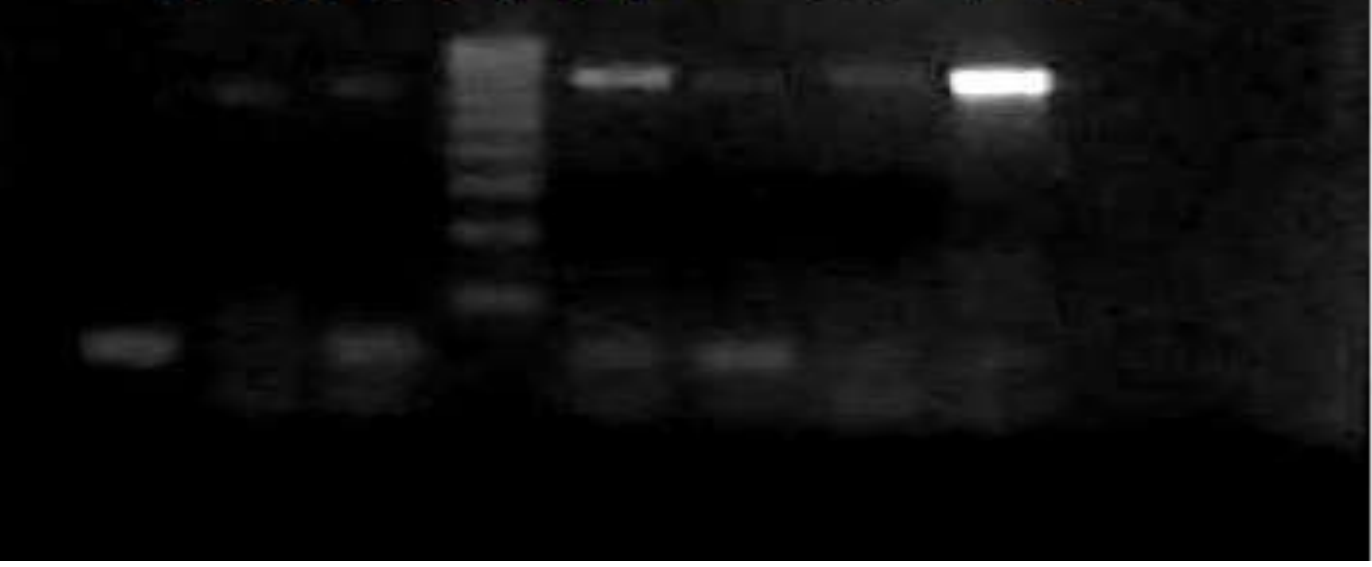

Figure (3):- PCR products with 766 bp molecular size of samples 24, 27 revealed strong bands but weak bands of samples 9, 18, 23 and 19 along with 100 bp molecular weight marker (M) (Second amplification).

\section{3-Results of sequencing of final PCR product}

The 7 positive samples were subjected for sequence analysis. $300 \mathrm{bp}$ fragment of the amplified product were sequenced. After sequence editing and trimming all sequences were analyzed using Bioedit program for alignment (figure 4 and figure 5).

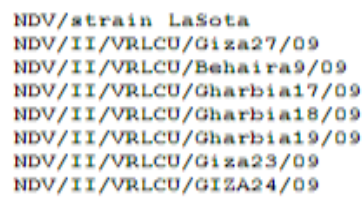

Figure (4):- Nucleotide alignment showing differences (similarities shown as dots) in comparison with Lasota strain (Accession No. AF077761.1) as representative for genotype II generated by BioEdit Bioinformatics program version 7.0.5. 


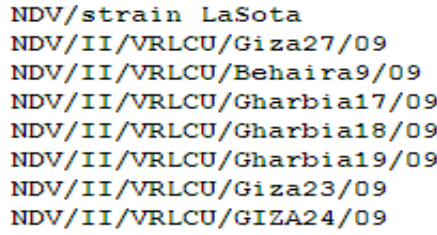

NDV/strain LaSota NDV/II/VRLCU/Giza27/09 NDV/II/VRLCU/Behaira9/09 NDV/II/VRLCU/Gharbia17/09 NDV/II/VRLCU/Gharbia18/09 NDV/II/VRLCU/Gharbia19/09 NDV/II/VRLCU/Giza23/09 NDV/II/VRLCU/GIZA24/09

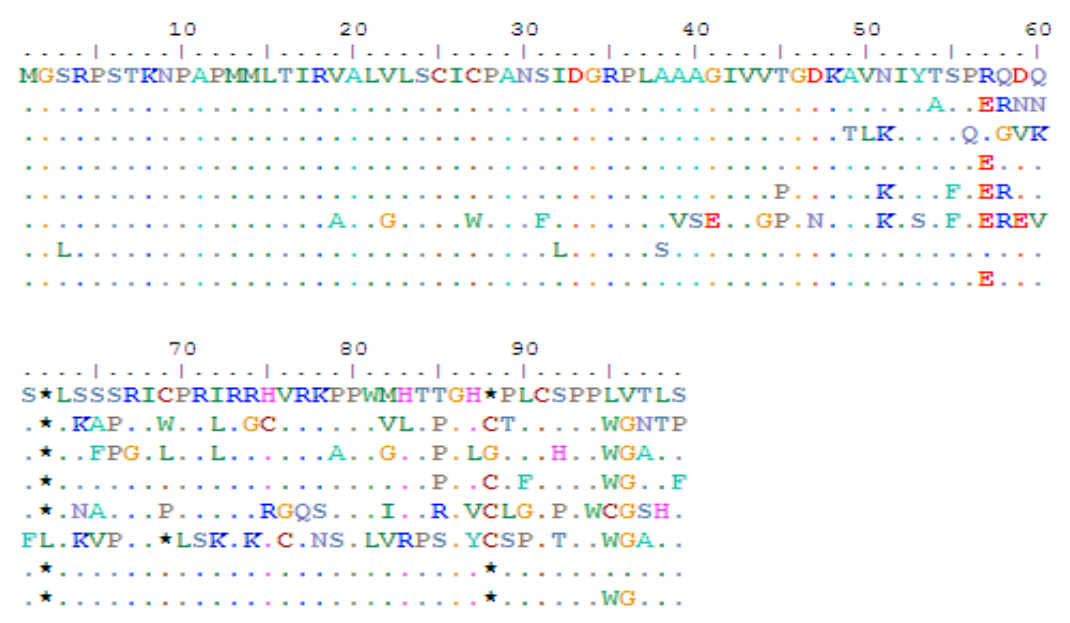

Figure (5):- Amino acid alignment showing differences (similarities shown as dots) in comparison with Lasota strain (Accession No. AF077761.1) as representative of genotype II generated by BioEdit Bioinformatics program version 7.0.5.

\subsection{Nucleotide and amino acid changes of local NDV isolates compared to Lasota strain}

Comparison of obtained local NDV isolates with Lasota strain demonstrated changes in nucleotides and amino acid in all isolates (Table 5).

Table (5):- Nucleotide and amino acid changes of the 7 local NDV isolates compared to Lasota strain.

\begin{tabular}{|l|l|l|}
\hline Local NDV isolates & No. of nucleotide changes & No. of amino acid changes \\
\hline NDV/Behaira/VRLCU/9/09 & 23 nucleotides & 21 amino acids \\
\hline NDV/ Gharbia /VRLCU/17/09 & 12 nucleotides & 7 amino acids \\
\hline NDV/Gharbia/VRLCU/18/09 & 52 nucleotides & 24 amino acids \\
\hline NDV/Gharbia/VRLCU/ 19/09 & 69 nucleotides & 43 amino acids \\
\hline NDV/Giza/VRLCU /23/09 & 6 nucleotides & 2 amino acids \\
\hline NDV/Giza/ VRLCU/24/09 & 10 nucleotides & 3 amino acids \\
\hline NDV/Giza/ VRLCU/27/09 & 40 nucleotides & 24 amino acids \\
\hline
\end{tabular}

\subsection{Homology percent of local NDV isolates compared to Lasota strain}

Comparison of obtained local NDV isolates with Lasota strain, high similarity was observed (Table 6).

Table (6):- Homology percent of nucleotide changes of the 7 local NDV isolates compared to Lasota strain.

\begin{tabular}{|l|c|}
\hline Local NDV isolates & Percent to Lasota \\
\hline NDV/Behaira/VRLCU/9/09 & $99 \%$ \\
\hline NDV/ Gharbia /VRLCU/17/09 & $99 \%$ \\
\hline NDV/Gharbia/VRLCU/18/09 & $93 \%$ \\
\hline NDV/Gharbia/VRLCU/ 19/09 & $92 \%$ \\
\hline NDV/Giza/VRLCU /23/09 & $98 \%$ \\
\hline NDV/Giza/ VRLCU/24/09 & $95 \%$ \\
\hline NDV/Giza/ VRLCU/27/09 & $96 \%$ \\
\hline
\end{tabular}

4-Result of Phylogenetic tree of NDV local isolates with different ten known global genotypes

The determined nucleotide sequences of the seven isolates (partial fragment about $300 \mathrm{bp}$ ) were aligned using BioEdit Bioinformatics program after sequence trimming. The aligned fragments were utilized with different global NDV genotypes for construction of phylogenetic tree using MEGA program version 4 by neighbor joining method, which revealed that all local NDV isolates were clustered with genotype II. 


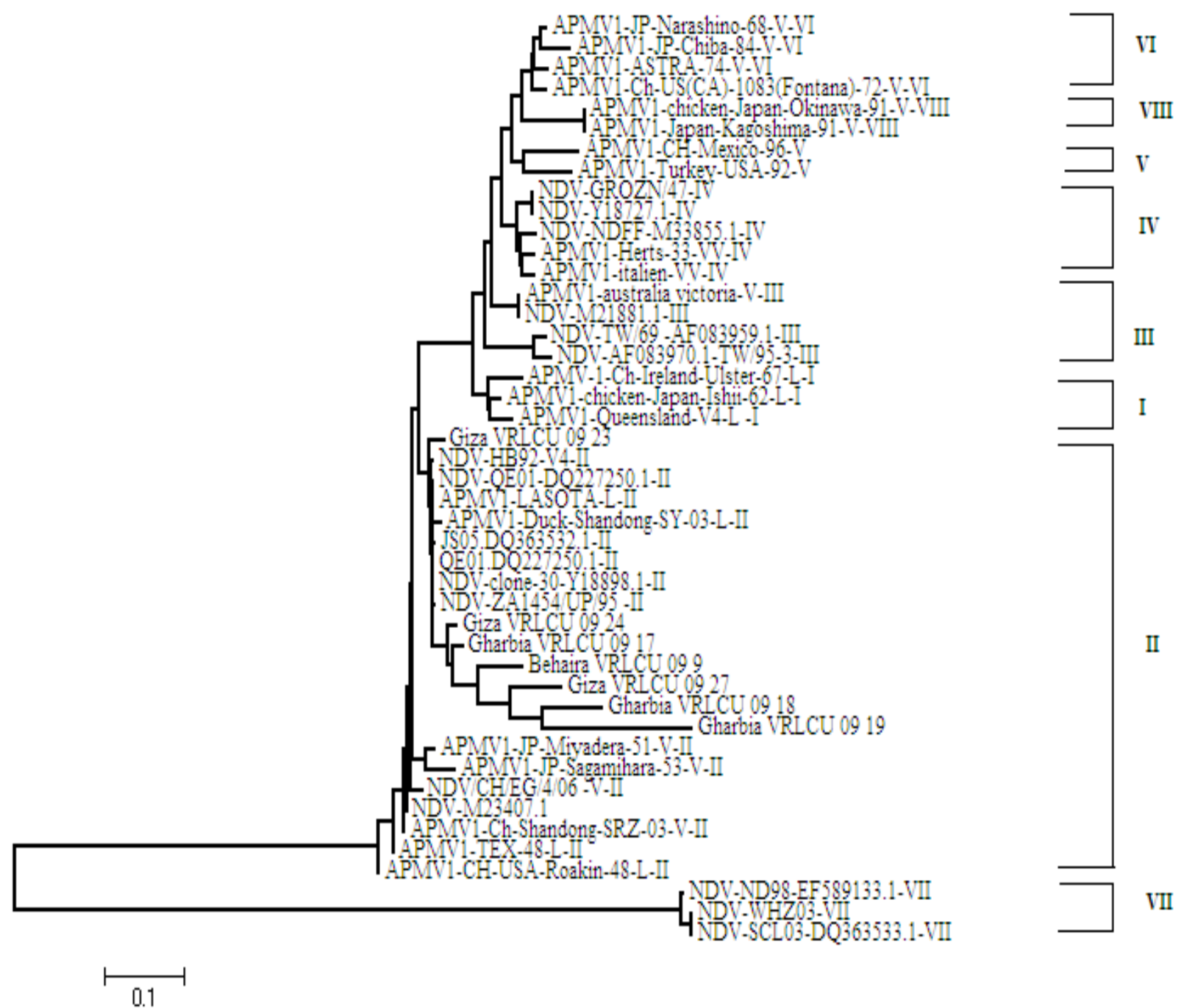

Figure (6):- Result of Phylogenetic tree of NDV local isolates with different ten known global genotypes.

\section{5-Result of Phylogenetic tree of NDV local isolates with different strains of NDV genotype II (first} probability)

Construction of the phylogenetic tree by neighbor joining method using MEGA 4.0 program of different strains of genotype II with seven NDV local isolates revealed that out of the seven local NDV isolates, 6 were clustered together and related to NDV Lasota L-II (Accession number AF077761) (Lasota like strain) while one isolate (NDV Giza/ VRLCU/ 09/ 23) was related to APMV1-Ch-Shandong-SRZ-03 strain (Accession number DQ417112). Although both (NDV/ Giza /VRLCU/ 09/ 23) and (NDV/ Giza/VRLCU/ 09/ 24) were obtained from one governorate but the former isolate was mutated and clustered as a separate isolate with less nucleotide changes than the latter isolate. 


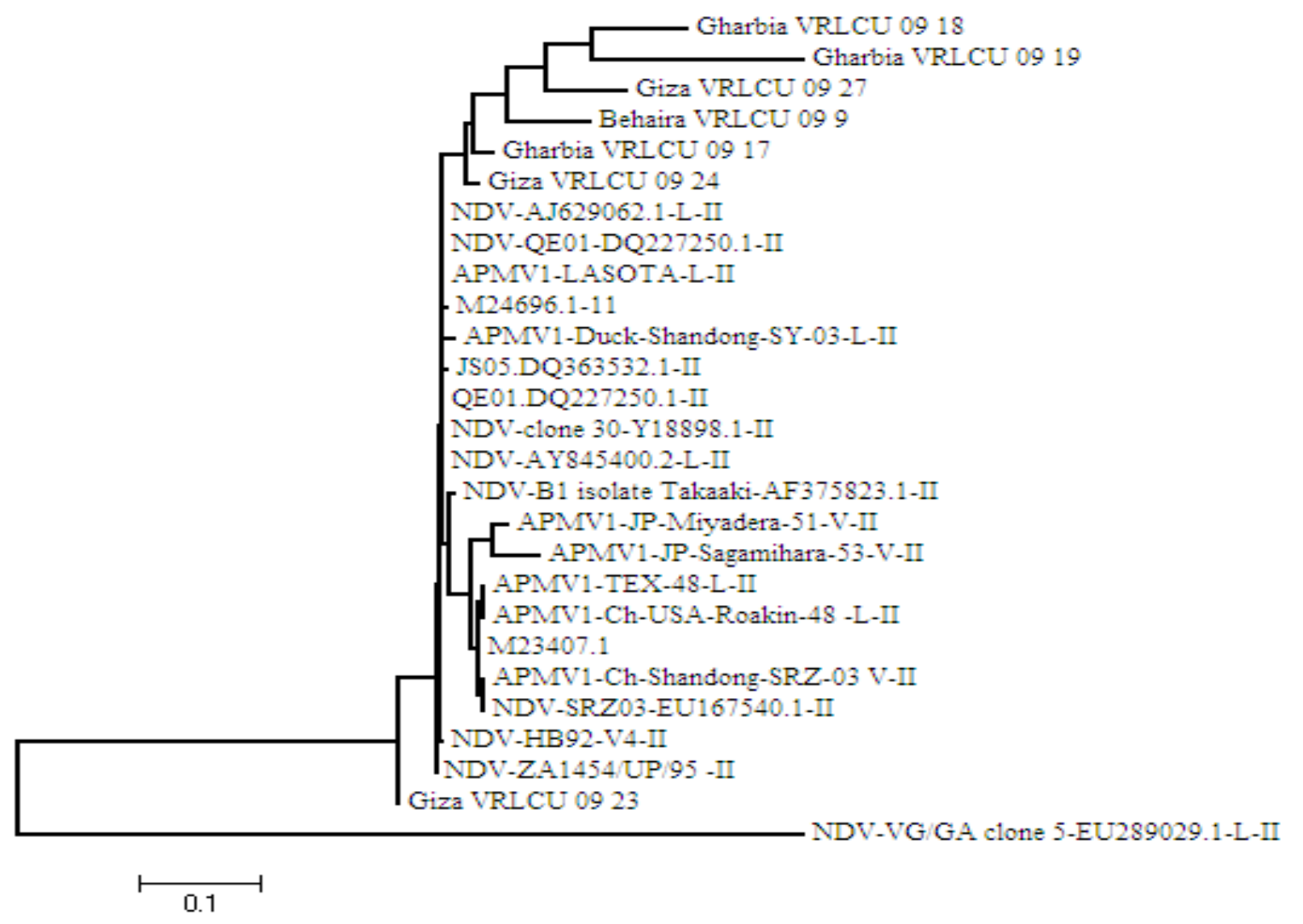

Figure (7):- Neighbor joining phylogenetic tree of seven local NDV isolates in comparison with NDV strains of genotype II (first probability).

6-Result of Phylogenetic tree of NDV local isolates with different strains of NDV genotype II (second probability)

Construction of the phylogenetic tree by neighbor joining method using MEGA 4.0 program of different strains of genotype II with seven NDV local isolates revealed that six of the seven NDV local isolates were related to Egyptian strain (NDV/Chicken/Egypt/2005/FJ939313.1) and increased pathogenicity than Lasota strain while one isolate (NDV Giza VRLCU 09 23) was related to clone 30 strain (Accession number Y18898.1). 


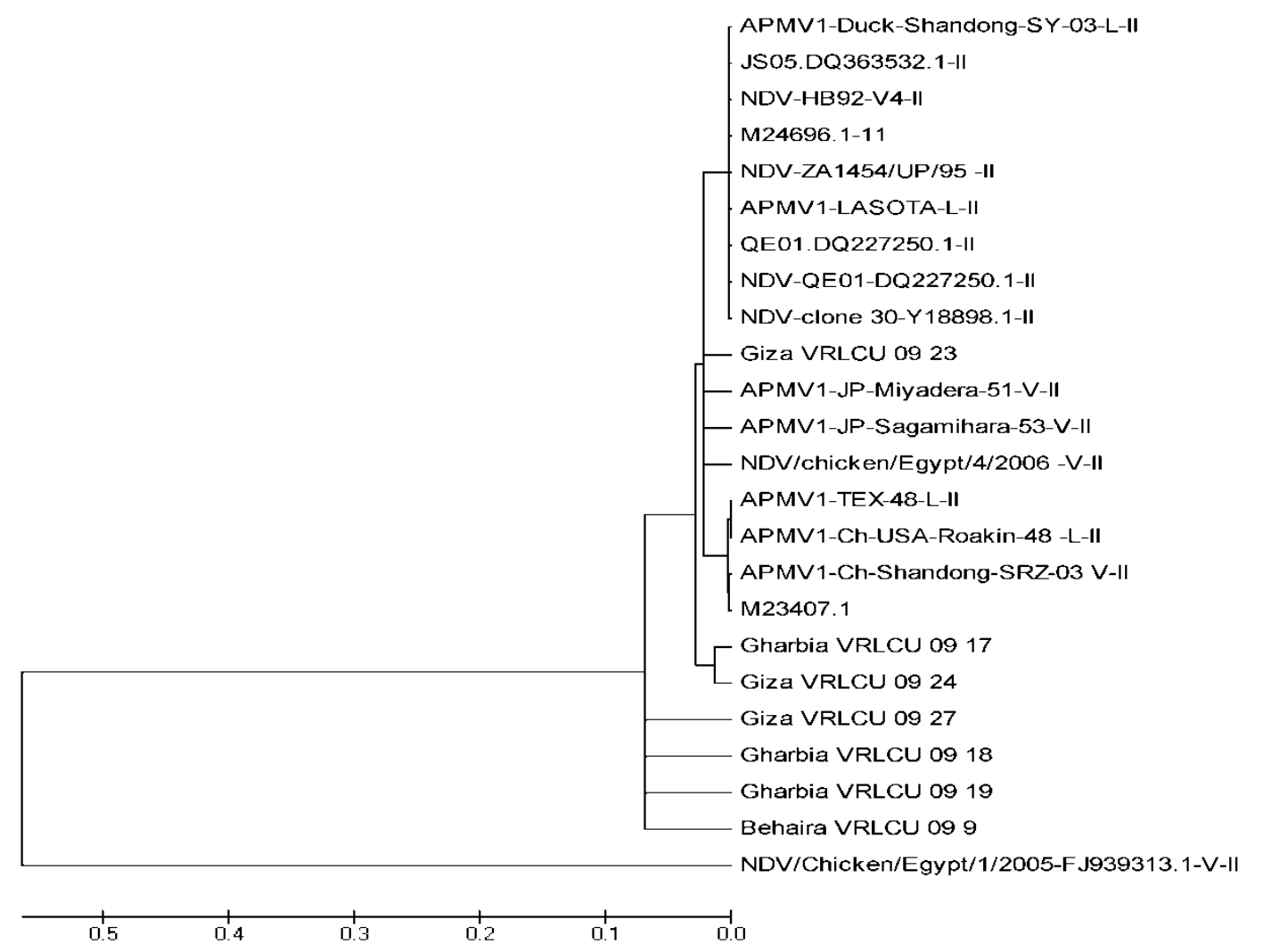

Figure (8):- Neighbor joining phylogenetic tree of seven local NDV isolates in comparison with NDV strains of genotype II (second probability).

\section{Discussion:-}

This study highlighted NDV outbreaks through collection of 50 different broiler field samples obtained from diverse governorates in Egypt. RT-PCR was standardized to ensure identification of amplified regions of $\mathrm{F}$ and $\mathrm{M}$ genes either in one or two steps and the obtained results demonstrated bands in expected size when analyzed in agrose gel stained with ethidium bromide and this confirmed specificity of used primers. In this respect, Jestin and Jestin (1991) developed the first RT-PCR for identification of NDV to amplify a $238 \mathrm{bp}$ of F gene and reported positive results that confirmed by restriction enzyme, the reaction was highly specific as there was no reaction with other avian viruses. For further sensitivity, Jestin et al., (1994) firstly described nested RT-PCR for identifying NDV. A $175 \mathrm{bp}$ of $\mathrm{F}$ gene was amplified directly from infected tissues of experimentally and field infected birds. In accordance with this technique Singh et al., (2005) applied RT-nested PCR directly on 30 field tissue samples and vaccine strains (F, LaSota, R B) were taken as positive control. All samples and vaccine strains yielded a band of $356 \mathrm{bp}$ on amplification of F gene NDV and three more field samples yielded a band of $216 \mathrm{bp}$ with nested PCR these findings according with results obtained in the present study. In contrast, sensitive and specific semi-nested RT-PCR was developed not only to detect different strains of NDV but also 13 strains class I NDV can be characterized which was feasible by the conventional methods (Zhang et al., 2010).For further characterization of the NDV, sequence was applied following RT-PCR. Similar conclusions were also obtained by Aldous et al., (2003) in which sequence of 375 nucleotides included the cleavage site of $F$ gene. The isolates divided into six distinct groups Considerable genetic heterogeneity was detected within avian NDV. In Egypt, complete genome sequence of virulent NDV was determined and phylogenetic analysis showed that Egyptian strain (Accession number FJ939313) was closely related to NDV strain isolated in China and the sequence of F gene cleavage site of Egyptian strain was identical to that of the NDV strain recently isolated in Mali (Mahmoud et al., 2009).

In agreement with the results obtained in the present study, local NDV isolates obtained in 2009 were related phylogenetically to genotype II (Lasota Accession number AF077761), Marin et al., (1996) stated about Nine NDV isolates that were analyzed for sequence variation. The viruses could be grouped phylogenetically with the B1 
vaccine-type but not $100 \%$ similar to B1 or Lasota NDV strains, indicating that minor genetic heterogeneity occurs among lentogenic field isolates of NDV.

Furthermore, Gribanov et al., (1999) determined complete nucleotide sequence of HN and F gene of BOR74 and BOR82 strains of NDV the BOR strains were grouped phylogenetically with the asymptomatic strains.

The same findings were obtained by Zi-shu et al., (2004) who detrmined complete nucleotides sequence of avirulent heat-resistance HB92 strain of NDV (Accession no. AY225110). Sequence analysis revealed that nucleotides homology of HB92 strain with virulent strain ZJ 1 were $83.9 \%$ and the homology compared with avirulent vaccine strain Lasota and B1 were $94 \%$ and 93\% respectively.

The same remarks were also noticed by seal et al., (2005) who determined full sequence for three NDV isolates. The isolates had F protein cleavage site sequence of low-virulence viruses that phylogenetically separated with other unique NDV isolates designated as a lineage 6 genotype.

As NDV infects wide population of avian species, it may have the potential to become virulent after circulation within chicken. This was investigated by Tsunekuni et al., (2010), Who determined complete sequence of avirulent NDV isolate Goose/ Alaska/415/91 and its virulent variant strain 9a5band suggested that in addition to the F cleavage site sequence, these two amino acids in HN protein are also related to the pathogenicity of NDV in chickens.

\section{Conclusion:-}

As the collected samples were obtained from breaks and vaccinated with live vaccines against NDV field infection with use of more than one type of vaccine provides selective immune pressures of the host leads to evolution of newly strains that may be virulent and exaggerated breaks (may be due to mutation) and this leads to conflict diagnosis between field lentogenic strains and viral field infection.

These field lentogenic strains may lead to evolve of new genotypes; this requires further classification of NDV genotypes across the world and may be source of infection by other pathogens.

This study emphasizes importance of NDV surveillance and reevaluation of vaccination programmes to control ND since novel genotypes or sub genotypes with panzootic potential may arise in the future.

Overall, the current study reports the first nucleotide sequence of lentogenic strains circulating among broiler chickens in the field in Egypt as associated with breaks.

\section{References:-}

1. Aldous, E.W. and Alexander, D.J. (2001): Detection and differentiation of Newcastle disease virus (avian paramyxovirus type 1). Avian Pathol, 30:117-128.

2. Aldous, E.W.; Mynn, J.K.; Banks, J. and Alexander, D.J. (2003): A molecular epidemiological study of avian paramyxovirus type 1 (Newcastle disease virus) isolates by phylogenetic analysis of a partial nucleotide sequence of the fusion protein gene. Avian Pathol. , 32: 239-257.

3. Alexander, D.J. and Senne, D.A. (2008): Newcastle disease, other avian paramyxoviruses, and pneumovirus infections. In: Saif, Y.M.; Fadly, A.M.; Glisson, J.R.; McDougald, L.R.; Nolan, L.K. and Swayne, D.E. (Eds.): Diseases of Poultry. Iowa State University Press, Ames, pp. 75-116.

4. Burleson, F.G.; Chambers, T.M. and Wiedbrauk, D.L. (1994): Virology a laboratory Manual. Academic Press, Harcourt Brace Jovanovich, Publishers, NewYork.

5. Berinstein, A.; Sellers, H.S.; King, D.J. and Seal, B.S. (2001): Use of heteroduplex mobility assay to detect differences in the fusion protein cleavage site coding sequence among Newcastle Disease Virus. J. Clin. Microbiol., 39: 3171-3178.

6. Collins, M.S.; Franklin, S.; Strong, I.; Meulemans, G. and Alexander, D.J. (1998): Antigenic and phylogenetic studies on a variant Newcastle disease virus using anti-fusion protein monoclonal antibodies and partial sequencing of the fusion protein gene. Avian. Pathol. 27: 90-96. 
7. De Leeuw, O. S.; Koch, G.; Hartog, L.; Ravenshorst, N. and Peeters, B.P.H. (2005): Virulence of Newcastle disease virus is determined by the cleavage site of the fusion protein and by both the stem region and globular head of the haemagglutinin-neuraminidase protein. J. Gen. Virol. , 86: 1759-1769.

8. Fauquet, C.M. and Fargette, D. (2005): International Committee on Taxonomy of Viruses and the 3,142 unassigned species. J. Virol., 2: 64.

9. Gribanov, O.G.; Starov, S.K.; Lomakin, A.I. ;Smolenskiĭ, V.I. Drygin, V.V. and Gusev, A.A. (1999): The nucleotide sequences of the HN gene and F gene fragment of Newcastle disease virus strains BOR74 and BOR82. J.Gen. Microbiol. Virol., (3):29-33.

10. Jestin, V. and Jestin, A. (1991): Detection of Newcastle disease virus RNA in infected allantoic fluids by in vitro enzymatic amplification (PCR). Arch.Virol., 118:151-161.

11. Jestin, V.; Cherbonnel, M. and Arnauld, C. (1994): Direct identification and characterization of A-PMV1 from suspicious organs by nested PCR and automated sequencing. Proceedings of the Joint First Annual Meetings of the National Newcastle Disease and Avian Influenza Laboratories of the European Communities, 1993 (pp.89-97). Brussels, Belgium.

12. Lamb, R. A. and Parks, G. D. (2007). Paramyxoviridae: the viruses and their replication. In Fields Virology, by Knipe, D. M.; Howley, P. M.; Griffin, D. E.; Lamb, R. A.; Martin, M. A., Roizman, B. and Straus, S. E. $5^{\text {th }}$ ed, pp. 1449-1496.Philadelphia, PA: Lippincott Williams and Wilkins.

13. Mahmoud, H. A.; Sachin, M.; Paldurai, K.A.; Megahed, M. M.; Ghanem, I. A.; Lebdah, M.A. and Samal, S. K. (2009):Complete genome sequence of a virulent Newcastle disease virus isolated from an outbreak in chickens in Egypt Virus Genes 39:234-237.

14. Marín, M.C.; Villegas, P.; Bennett, J.D. and Seal, B.S.( 1996): Virus characterization and sequence of the fusion protein gene cleavage site of recent Newcastle disease virus field isolates from the southeastern United States and Puerto Rico. Avian Dis., 40(2):382-90.

15. Mase, M.; Imai, K.; Sanada, Y.; Sanada, N.;Yuasa, N.; Imada, T.;Tsukamoto, K. and Yamaguchi, S. (2002): Phylogenetic analysis of Newcastle disease virus genotypes isolated in Japan. J. Clin. Microbiol., 40:3826-3830.

16. Miller, P.J.; Decanini, E.L. and Afonso, C.L. (2010): Newcastle disease: evolution of genotypes and the related diagnostic challenges. Infect. Genet. Evol., 10:26-35.

17. Sambrook, J.; Fritsch, E.F. and Maniatis, T. (1989): Molecular cloning A Laboratory Manual second edition.Cold Spring HarborLaboratory, NY, USA

18. Seal , B. S.; King , D. J; and Bennett, J. D. (1995):Characterization of Newcastle disease virus isolates by reverse transcription PCR coupled to direct nucleotide sequencing and development of sequence database for pathotype prediction and molecular epidemiological analysis. J. Clin. Microbiol., 33 (10):2624-2630.

19. Seal, B.S.; Wise, M.G.; Pedersen, J.C.; Senne, D.A.; Alvarez, R.;Scott, M.S.; King, D.J.; Yu, Q. and Kapczynski, D.R.( 2005): Genomic sequences of low virulence avian paramyxovirus-1 (Newcastle disease virus) isolates obtained from live-bird markets in North America not related to commonly utilized commercial vaccine strains.Vet. Microbiol., 106: 7-16.

20. Singh, K.; Jindal, N.; Gupta, S.L.; Gupta, A.K. and Mittal, D. (2005): Detection of Newcastle Disease Virus Genome from the Field Outbreaks in Poultry by Reverse Transcription - Polymerase Chain Reaction International. J. Poult.Sci., 4 (7): 472-475.

21. Tsunekuni, R.; Ito, H. ; Otsuki , K.;Kida, H. and Ito, T.; (2010): Genetic comparisons between lentogenic Newcastle disease virus isolated from waterfowl and velogenic variants. Virus Genes, 40:252-255.

22. Zhang, L.; Pan, Z. ; Geng, S.; Chen, X.; Hu, S.; Liu, H.; Wu, Y.; Jiao, X. and Liu, X. (2010):Sensitive, semi-nested RT-PCR amplification of fusion gene sequences for the rapid detection and differentiation of Newcastle disease virus. Res.Vet. Sci., 89:282-289.

23. Zi-shut, P.; Yu-dong, C.; Hua-birrz, S.; Ju, Y.; Zhong-lian, X.; Guo-yuan, W. and Chu-yu, Z. (2004): Complete Nucleotide Sequence of a Newly Avirulent Newcastle Disease Virus Hubei 92(HB92) Strain Wuhan University. J. Nat. Sci., 9 (3): 381-387. 